\title{
Clinical evaluation of the levels of 12 cytokines in serum/plasma under various storage conditions using evidence biochip arrays
}

\author{
GUANG-HONG GUO, JIN DONG, XIN-HONG YUAN, ZHEN-NAN DONG and YA-PING TIAN \\ Department of Clinical Biochemistry, Chinese PLA General Hospital, Beijing 100853, P.R. China
}

Received September 13, 2012; Accepted December 28, 2012

DOI: $10.3892 / \mathrm{mmr} .2013 .1263$

\begin{abstract}
Cytokines are a group of peptides which form a sophisticated network to modulate multiple cellular events. Within such a network, and through complex feedback mechanisms, cytokine functions are largely interdependent and closely associated with a number of pathological processes. In the present study, the EVIDENCE 180 system was used to study the effects of storage temperature and repeated freeze/thaw cycles on the concentration of 12 cytokines in various sample types. Samples were collected from 9 healthy volunteers and stored by 3 methods: gel, glass and lithium heparin $(\mathrm{LH})$ tubes. Immediately following collection, the concentration of each cytokine in the samples was measured. Cytokine concentrations of the 3 sample types that did not undergo repeated freeze/thaw cycles were compared with those subjected to 1-10 freeze/thaw cycles. In addition, the dynamic changes of 6 sample types which were stored at $4^{\circ} \mathrm{C}$ for $6 \mathrm{~h}$ to 6 days was analyzed. In addition, the withinand between-run precision of 12 cytokines on the biochip array was evaluated. Interleukin (IL)-8, vascular endothelial growth factor (VEGF) and epidermal growth factor (EGF) concentrations were lower in plasma compared with serum. Cytokine levels in serum and plasma were affected by several freeze/thaw cycles with IL-1 $\beta,-4$ and -10 increasing significantly following 1 freeze/thaw cycle and remaining at stable increased levels for the duration of the additional 9 cycles. In separated serum samples in gel and glass tubes stored at $4^{\circ} \mathrm{C}$ for 6 days, no difference in concentration of the 12 cytokines was identified. In the other 4 sample types, IL-8, VEGF, tumor necrosis factor $\alpha$ and EGF levels were altered when stored at $4^{\circ} \mathrm{C}$. Results indicate that the EVIDENCE 180 system is stable and plasma was observed as the best sample type to determine concentration of the 12 cytokines using this biochip array. Repeated freeze/thaw cycles and storage at $4^{\circ} \mathrm{C}$ was identified to affect the concentration of the 12 cytokines.
\end{abstract}

Correspondence to: Professor Ya-Ping Tian, Department of Clinical Biochemistry, Chinese PLA General Hospital, 28 Fu-xing Road, Beijing 100853, P.R. China

E-mail: tianyp61@gmail.com

Key words: biochip, cytokine, plasma, serum, storage
The current study demonstrates that repeated freeze/thaw cycles of samples must be avoid. In addition, results indicate that plasma or serum must be separated immediately following centrifugation and sample concentration should be measured as soon as possible.

\section{Introduction}

In recent years, biochip technology has developed extremely rapidly and may soon be utilized in routine clinical analysis. Cytokines are known to be important substances in the human body, possessing multiple biological activities, promoting target cell proliferation, enhancing anti-inflammation effects and NK cell activity, modulating cell metabolism and mediating inflammation. Variations in the concentration of cytokines in vivo are associated with the pathological processes of a number of diseases (1).

The study of cytokines has developed from four independent study areas. The first and most significant area is immunology, specifically the study of lymphokines. The second source of cytokine research is associated with interferons (IFNs). Hematopoietic growth or colony-stimulating factors is the third area and the study of nonhematopoietic growth factors is the fourth source. The role of cytokines in the regulation of immune and inflammatory responses is now clearly recognized and studies on cytokines have led to their association with numerous pathological conditions.

Cytokines are markedly associated with roles in diseases, particularly chronic diseases during which cytokines are released in response to infection or inflammation. In a mouse model, blockage of interleukin (IL)-10 production was identified as a potential therapeutic for pulmonary tuberculosis (2). In an additional study, IL-10 was found to be critical for protecting the cerebral microcirculation from spirochaetal injury by inhibiting the effects of tumor necrosis factor (TNF) (3). IL-10 levels are associated with early treatment failure of advanced stage Hodgkin's lymphoma and are independent of current known clinical factors (4). Serum TNF $\alpha$, IL-6 and nitric oxide (NO) levels have also been identified as biomarkers during systemic inflammatory response in chronic obstructive pulmonary disease (COPD) patients and, to a lesser degree, in COPD exacerbation or monitoring recovery following exacerbation (5). Elevated levels of TNFa and IL- 6 have also been reported in coronary artery disease (CAD) and systolic heart failure (6) and are associated 
with the immunoinflammatory activation process. Finally, overproduction of IL-6 accelerates pathogenesis of CAD in Chlamydia pneumonia (7). A previous study demonstrated that inhaling NO may reduce primary graft dysfunction following lung transplantation by downregulation of the inflammatory response through reduction of IL concentrations, including IL-6 and -8 (8). Alterations in cytokine levels regulate gene expression. For example, TNF $\alpha$ and IL-1 $\beta$ induce NO production which regulates MMP-9 and TIMP-1 expression in the human mesangial cell line (9). Monocyte chemoattractant protein-1 (MCP-1) is induced by NF- $\kappa \mathrm{B}$ activation in homocysteine which is an independent risk factor for cardiovascular disorders when overaccumulated in the blood (10). In addition, serum cytokine levels, including IL-6, $-1 \beta,-2,-4,-5,-7,-8,-10,-12,-13$ and -17 , TNF $\alpha$, granulocyte colony-stimulating factor (G-CSF), granulocyte macrophage colony-stimulating factor (GM-CSF), macrophage inflammatory protein (MIP)-1 $\beta$ and MCP-1, have been found to vary in middle-aged females and may be associated with the progression of various diseases in pre- and postmenopausal females (11). Vascular endothelial growth factor (VEGF) levels in peripheral blood are used to determine asthma progression by analyzing elevation in airway inflammation and remodeling in asthma (12). Therefore, cytokines are important in pathogenesis and process of diseases. At present, a significant issue remains unsolved concerning the storage and evaluation of cytokine samples.

The EVIDENCE 180 analyzer is a fully automated Biochip Array system and a number of immunoassay-based multi-analyte arrays have been developed for this system. The Cytokine Array biochip quantitatively and simultaneously analyzes levels of IL- $1 \alpha,-1 \beta,-2,-4,-6,-8$ and -10 , VEGF, IFN $\gamma$, epidermal growth factor (EGF), MCP-1 and TNF $\alpha$.

In the present study, the stability of cytokines in various sample types and the effect of different storage conditions on the samples was analyzed. In addition, the within- and between-run precision of the EVIDENCE 180 system was evaluated.

\section{Materials and methods}

Study population. Nine individual volunteers (6 males, 18-46 years old; 3 females, 19-36 years old) provided blood samples for the current study. Informed consent was obtained from each volunteer and all individuals passed a physical examination. This study was conducted in accordance with the Helsinki Declaration and approved by the Medical Ethics Committee of the Chinese PLA General Hospital (Beijing, China).

Comparison of cytokine levels in various samples. Nine volunteers provided $9 \mathrm{ml}$ of whole blood collected into gel, glass and lithium heparin (LH) tubes (all sample tubes purchased from BD Biosciences, Franklin Lakes, NJ, USA). Samples were obtained in the morning following a 12-h fast. Each type of sample tube held $3 \mathrm{ml}$ whole blood. Blood samples were kept at room temperature for $30 \mathrm{~min}$ and then centrifuged for $10 \mathrm{~min}$ at 3,000 rpm. Following centrifugation, the serum and plasma samples of each volunteer were immediately separated and analyzed to compare cytokine levels.
Freezelthaw cycles study. Briefly, each volunteer provided $30 \mathrm{ml}$ whole blood in total into gel, glass and LH tubes in the morning following a 12-h fast. Each sample tube held $10 \mathrm{ml}$ whole blood. Blood samples were kept at room temperature for $30 \mathrm{~min}$ and then centrifuged for $10 \mathrm{~min}$ at 3,000 rpm. Following centrifugation, samples (serum or plasma) were divided into one $0.5-\mathrm{ml}$ and thirty $0.3-\mathrm{ml}$ aliquots. The 3 types of $0.5-\mathrm{ml}$ aliquot from each volunteer were analyzed immediately and the results were used as baseline values for the 12 cytokines. The additional thirty $0.3-\mathrm{ml}$ aliquots, stored by 3 methods, from each volunteer (total, 270 aliquots) were stored at $-80^{\circ} \mathrm{C}$ and thawed $1,2,3,4,5,6,7,8,9$ and 10 times at room temperature for $2 \mathrm{~h}$ and then stored at $-80^{\circ} \mathrm{C}$ until analysis. Concentration of the 12 cytokines in each sample was compared with baseline values and plotted against the number of freeze/thaw cycles (13).

Refrigeration study. Each volunteer provided $30 \mathrm{ml}$ whole blood in total into 2 gel, 2 glass and 2 LH tubes in the morning following a 12-h fast. Each tube held $5 \mathrm{ml}$ whole blood. Blood samples were kept at room temperature for $30 \mathrm{~min}$ and then centrifuged for $10 \mathrm{~min}$ at 3,000 rpm. Following centrifugation, samples were subjected to various procedures to produce 6 samples from each volunteer, including separated and unseparated serum in gel tubes, separated and unseparated plasma in LH tubes and separated and unseparated serum in glass tubes. Samples were analyzed immediately and the results used as the baseline values for the cytokines. Additional samples were stored at $4^{\circ} \mathrm{C}$ for 6 and $12 \mathrm{~h}$ and $1,2,3,4,5$ and 6 days prior to analysis. Cytokine concentrations in each sample type were compared with baseline values.

Within- and between-run precision. To evaluate within-run precision of the 12 cytokines, high, mid and low concentration control sera (no. 2279) were tested 10 times simultaneously. To evaluate between-run precision of the 12 cytokines, high, mid and low concentration control sera (no. 2295) were tested over 10 days, 1 time/day. Precision was expressed as coefficient of variation $(\mathrm{CV})$. All controls were obtained from Randox Laboratories (Crumlin, UK).

Analyzer and reagent. The EVIDENCE 180 (14) Biochip Analyzer system and Cytokine Array I kits (nos. 0857 and 0658, both Randox Laboratories) were used to detect serum levels of 12 cytokines.

Statistical analysis. SPSS 13.0 software was used to perform statistical analyses. ANOVA test was used and $\mathrm{P}<0.05$ was considered to indicate a statistically significant result.

\section{Results}

Cytokine levels in various samples. Cytokine concentrations were not found to be significantly different between serum samples in the gel and glass tubes $(\mathrm{P}>0.05)$. However, cytokine levels were identified to be significantly different between serum and plasma samples. IL-8, VEGF and EGF levels in plasma were significantly lower compared with serum $(\mathrm{P}<0.01$; Table I). Cytokine levels in plasma were identified to be more stable than in serum samples (Fig. 1). 


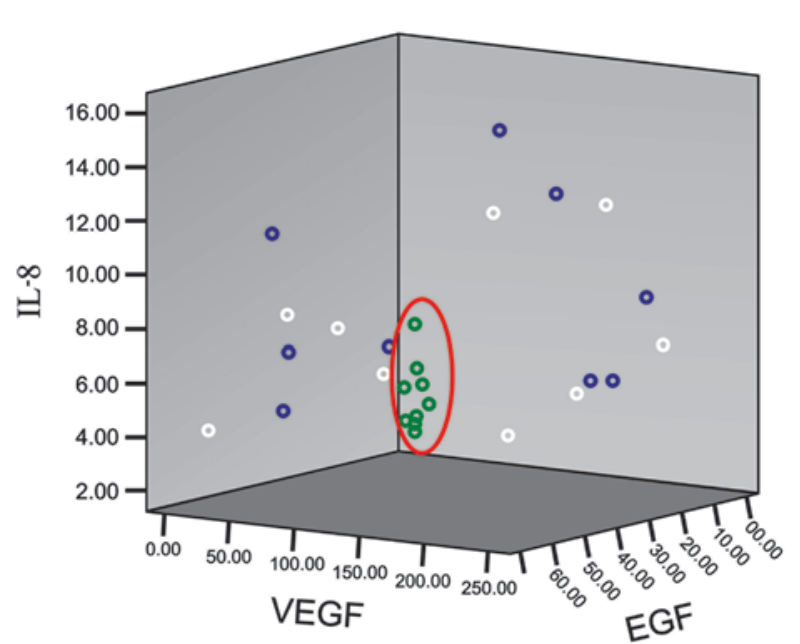

Figure 1. Levels of IL-8, VEGF and EGF in various samples. $x-, y-$ and $z$-axes show the concentration of IL-8, VEGF and EGF (ng/l), respectively. Blue, white and green rings represent serum in gel and glass tubes and plasma in LH tubes, respectively. The red ring shows the plasma results. IL, interleukin; VEGF, vascular endothelial growth factor; EGF, epidermal growth factor; $\mathrm{LH}$, lithium heparin.
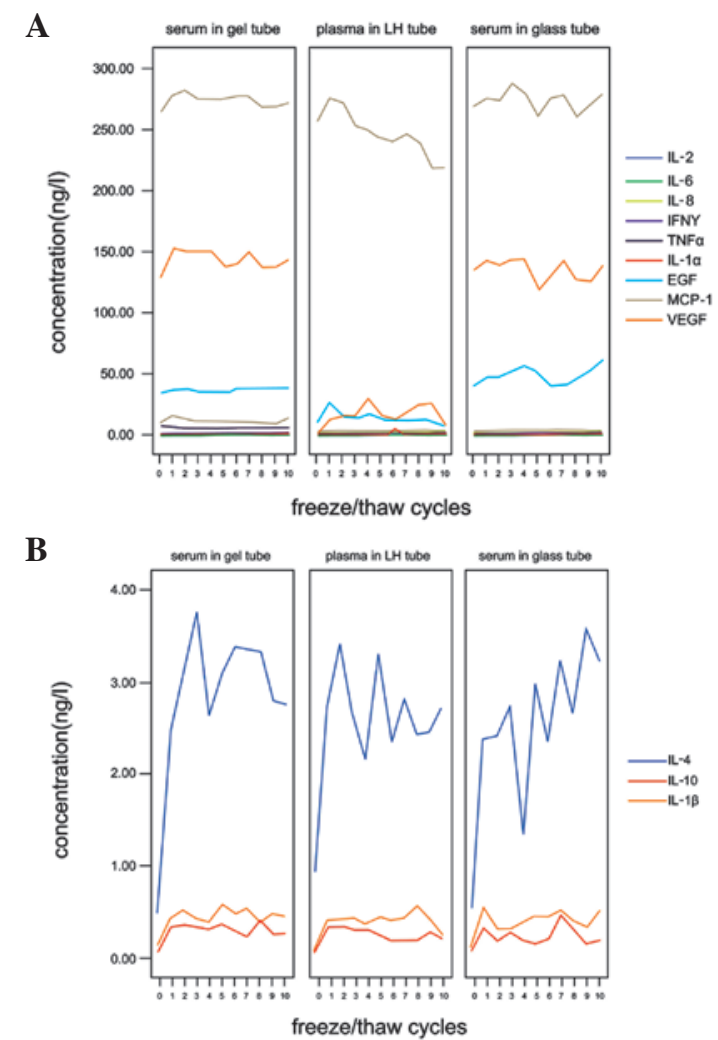

Figure 2. Effect of multiple freeze/thaw cycles on cytokine levels. (A) Nine cytokines of 3 sample types exhibited no alterations in concentration following 10 freeze/thaw cycles. (B) IL-1 $\beta,-4$ and -10 of 3 sample types. Concentrations increased by 3-5-fold following only 1 freeze/thaw cycle. IL, interleukin; VEGF, vascular endothelial growth factor; IFN, interferon; EGF, epidermal growth factor; MCP, monocyte chemotactic protein; TNF, tumor necrosis factor.

Freezelthaw cycles. No significant difference in concentration following 10 freeze/thaw cycles was found for 9 cytokines in the 3 sample types $(\mathrm{P}>0.05)$; gel, glass and LH tubes. These cytokines were IL-1 $\alpha,-2,-6$ and $-8, \mathrm{TNF} \alpha, \mathrm{EGF}, \mathrm{VEGF}, \mathrm{IFN} \gamma$
A
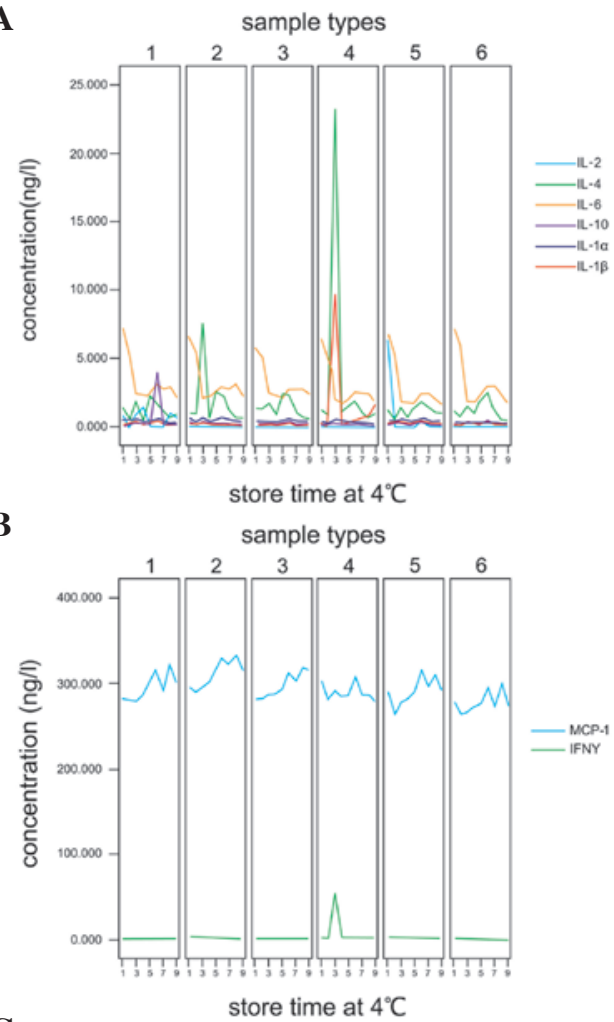

C

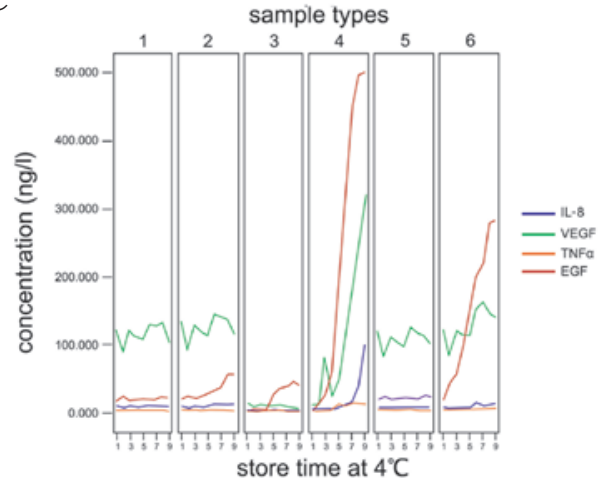

Figure 3. Cytokine concentrations following refrigeration. (A and B) Eight cytokines of 6 sample types were unchanged following storage at $4^{\circ} \mathrm{C}$ for 6 days. (C) Effect of storage at $4^{\circ} \mathrm{C}$ on IL-8, VEGF, TNF $\alpha$ and EGF concentrations in various sample types. Sample types 1-6 reveal separated serum in gel tube, separated plasma in LH tube, unseparated serum in gel tube, unseparated plasma in LH tube, separated serum in glass tube and unseparated serum in glass tube, respectively. Storage times 1-9 include 6 sample types stored at $4^{\circ} \mathrm{C}$ for 0,6 and $12 \mathrm{~h}$ and $1,2,3,4,5$ and 6 days, respectively. IL, interleukin; VEGF, vascular endothelial growth factor; IFN, interferon; EGF, epidermal growth factor; MCP, monocyte chemotactic protein-1; TNF, tumor necrosis factor; $\mathrm{LH}$, lithium heparin.

and MCP-1 (Fig. 2A). IL-1 $\beta,-4$ and -10 levels in the 3 sample types increased at least 3-5-fold following 1 freeze/thaw cycle, stabilizing at these levels during the additional 9 freeze/thaw cycles (Fig. 2B).

Refrigeration study. Following storage at $4^{\circ} \mathrm{C}$ for 6 days, levels of 8 cytokines were unchanged in the 6 sample types; separated and unseparated serum in gel tubes, separated and unseparated plasma in LH tubes and separated and unseparated serum in glass tubes. These cytokines were IL- $1 \alpha,-1 \beta,-2,-4,-6$ and -10 , MCP-1 and IFN $\gamma$ (Fig. 3A and B). By contrast, IL-8, VEGF, 
Table I. Cytokine level in various samples (ng/l).

\begin{tabular}{lccc}
\hline Cytokines & Serum in gel tube & Serum in glass tube & Plasma in LH tube \\
\hline IL-1 $\alpha$ & $0.029 \pm 0.086$ & $0.088 \pm 0.263$ & 0 \\
IL-1 $\beta$ & $0.128 \pm 0.254$ & $0.120 \pm 0.237$ & $0.068 \pm 0.204$ \\
IL-2 & 0 & $0.297 \pm 0.890$ & 0 \\
IL-4 & $0.483 \pm 1.448$ & $0.539 \pm 1.618$ & $0.922 \pm 1.837$ \\
IL-6 & $1.233 \pm 2.245$ & $1.328 \pm 2.403$ & $1.331 \pm 2.296$ \\
IL-8 & $8.621 \pm 3.433$ & $7.526 \pm 2.777$ & $3.529 \pm 1.296^{\mathrm{a}, \mathrm{b}}$ \\
IL-10 & $0.064 \pm 0.192$ & $0.068 \pm 0.204$ & $0.053 \pm 0.160$ \\
VEGF & $128.09 \pm 75.470$ & $134.225 \pm 78.263$ & $9.639 \pm 5.039^{\mathrm{a}, \mathrm{b}}$ \\
IFN $\gamma$ & $1.141 \pm 1.441$ & $1.212 \pm 1.507$ & $1.205 \pm 1.155$ \\
EGF & $33.967 \pm 22.337$ & $38.936 \pm 21.629$ & $0.510 \pm 1.039^{\mathrm{a}, \mathrm{b}}$ \\
MCP-1 & $263.973 \pm 49.372$ & $286.272 \pm 59.695$ & $256.907 \pm 45.370$ \\
TNF $\alpha$ & $8.126 \pm 9.858$ & $4.009 \pm 0.938$ & $2.896 \pm 0.834$ \\
\hline
\end{tabular}

Values are presented as mean $\pm \mathrm{SD} .{ }^{\mathrm{a}} \mathrm{P}<0.01$ vs. serum cytokines in gel tubes. ${ }^{b} \mathrm{P}<0.01 \mathrm{vs}$. serum cytokines in glass tubes. Data are presented as the mean \pm SD. IL, interleukin; VEGF, vascular endothelial growth factor; IFN, interferon; EGF, epidermal growth factor; MCP, monocyte chemotactic protein; TNF, tumor necrosis factor; LH, lithium heparin.

Table II. Within and between run precision of 12 cytokines $(n=10)$.

\begin{tabular}{|c|c|c|c|c|c|c|}
\hline \multirow[b]{2}{*}{ Cytokines } & \multicolumn{3}{|c|}{ Within run precision, CV (\%) } & \multicolumn{3}{|c|}{ Between run precision, $\mathrm{CV}(\%)$} \\
\hline & Low & Mid & High & Low & Mid & High \\
\hline IL- $1 \alpha$ & 2.72 & 3.67 & 5.47 & 4.40 & 3.57 & 4.15 \\
\hline IL-1 $\beta$ & 7.15 & 6.05 & 6.24 & 4.44 & 4.05 & 3.86 \\
\hline IL-2 & 8.49 & 5.42 & 2.53 & 3.90 & 2.41 & 2.14 \\
\hline IL-4 & 6.51 & 7.95 & 8.78 & 5.43 & 6.32 & 4.04 \\
\hline IL-6 & 4.75 & 5.80 & 8.77 & 9.90 & 5.58 & 6.49 \\
\hline IL-8 & 7.91 & 3.85 & 8.39 & 6.63 & 6.45 & 6.34 \\
\hline IL-10 & 3.95 & 5.42 & 4.20 & 2.20 & 3.27 & 3.58 \\
\hline VEGF & 8.22 & 5.77 & 8.49 & 8.77 & 6.98 & 7.43 \\
\hline $\mathrm{IFN} \gamma$ & 5.14 & 8.42 & 5.50 & 6.20 & 6.50 & 9.40 \\
\hline EGF & 4.34 & 4.19 & 5.40 & 3.80 & 1.77 & 3.86 \\
\hline MCP-1 & 4.47 & 3.00 & 3.98 & 5.07 & 2.42 & 3.36 \\
\hline $\mathrm{TNF} \alpha$ & 6.81 & 6.20 & 7.84 & 6.25 & 4.03 & 5.44 \\
\hline
\end{tabular}

IL, interleukin; VEGF, vascular endothelial growth factor; IFN, interferon; EGF, epidermal growth factor; MCP, monocyte chemotactic protein; $\mathrm{TNF}$, tumor necrosis factor; $\mathrm{CV}$, coefficient of variation.

TNF $\alpha$ and EGF concentrations in the 6 sample types were identified at different levels in different samples (Fig. 3C).

In separated serum in gel tube samples, no significant difference in levels of the 4 cytokines were identified when stored at $4^{\circ} \mathrm{C}$ for 6 days. In the unseparated serum in gel tube samples, levels of 3 cytokines were observed to be significantly different. IL-8 levels increased following storage at $4^{\circ} \mathrm{C}$ for 3 days. EGF increased by $>2$-fold on day 4 from 18.98 to $38.30 \mathrm{ng} / \mathrm{l}$ and then increased to $56.33 \mathrm{ng} / \mathrm{l}$ at day 6 . TNF $\alpha$ levels decreased on day 6 .

In separated plasma in LH tube, EGF levels were found to be significantly increased on day 2 following storage at $4{ }^{\circ} \mathrm{C}$. In unseparated plasma in $\mathrm{LH}$ tube, 4 cytokines were noted at significantly increased concentrations. EGF levels increased extremely rapidly, $>6$-fold following storage at $4^{\circ} \mathrm{C}$ for $6 \mathrm{~h}$. EGF concentration was $>500 \mathrm{ng} / \mathrm{l}$ at day 6 . VEGF levels increased at day 1 , exceeding 25 times the baseline concentration at day 6 . IL-8 levels increased from day 2 and were also found to exceed 25 times the baseline levels by day 6 . TNF $\alpha$ increased from day 2 .

In separated serum samples in glass tubes, no significant difference in levels of IL-8, VEGF, TNF $\alpha$ and EGF was identified when samples were stored at $4^{\circ} \mathrm{C}$ for 6 days. In unseparated serum samples in glass tubes, EGF levels were detected at $>2$ times baseline levels following storage at $4^{\circ} \mathrm{C}$ for $6 \mathrm{~h}$. At day 6, EGF concentration was $281.92 \mathrm{ng} / \mathrm{l}$. IL-8 
Table III. Within and between run control levels of 12 cytokines $(n=10)$.

\begin{tabular}{|c|c|c|c|c|c|c|}
\hline \multirow[b]{2}{*}{ Cytokines } & \multicolumn{3}{|c|}{ Within run control levels (ng/l) } & \multicolumn{3}{|c|}{ Between run control levels (ng/l) } \\
\hline & Low & Mid & High & Low & Mid & High \\
\hline IL-1 $\alpha$ & $15.45 \pm 0.42$ & $58.47 \pm 2.14$ & $245.08 \pm 13.41$ & $62.3 \pm 2.74$ & $126.4 \pm 4.52$ & $258.7 \pm 10.74$ \\
\hline IL-1 $\beta$ & $7.72 \pm 0.55$ & $32.27 \pm 1.95$ & $123.86 \pm 7.73$ & $31.3 \pm 1.39$ & $62.9 \pm 2.55$ & $128.2 \pm 4.95$ \\
\hline IL-2 & $9.68 \pm 0.82$ & $51.3 \pm 2.78$ & $492.27 \pm 12.47$ & $121.3 \pm 4.72$ & $245.5 \pm 5.93$ & $505.5 \pm 10.81$ \\
\hline IL-4 & $32.82 \pm 2.14$ & $227.3 \pm 18.06$ & $906.7 \pm 79.62$ & $246.5 \pm 13.4$ & $492.6 \pm 31.11$ & $978.7 \pm 39.5$ \\
\hline IL-6 & $4.04 \pm 0.19$ & $17.63 \pm 1.02$ & $135.69 \pm 11.99$ & $32.7 \pm 3.6$ & $75.8 \pm 4.23$ & $154.9 \pm 10.04$ \\
\hline IL-8 & $9.64 \pm 0.76$ & $121.87 \pm 4.7$ & $991.97 \pm 83.23$ & $259.5 \pm 17.22$ & $512.8 \pm 33.1$ & $1047.9 \pm 66.49$ \\
\hline IL-10 & $13.35 \pm 0.53$ & $59.19 \pm 3.21$ & $229.94 \pm 9.67$ & $61.3 \pm 1.35$ & $122.0 \pm 3.99$ & $244.2 \pm 3.27$ \\
\hline VEGF & $32.18 \pm 2.64$ & $104.15 \pm 6.01$ & $712.76 \pm 60.48$ & $112.5 \pm 9.87$ & $253.8 \pm 17.72$ & $801.4 \pm 59.54$ \\
\hline $\mathrm{IFN} \gamma$ & $87.74 \pm 4.51$ & $260.3 \pm 21.92$ & $433.11 \pm 23.84$ & $125.9 \pm 7.8$ & $229.3 \pm 14.9$ & $523.7 \pm 49.21$ \\
\hline EGF & $14.58 \pm 0.63$ & $64.3 \pm 2.7$ & $245.84 \pm 13.27$ & $60.3 \pm 2.29$ & $124.4 \pm 2.2$ & $243.7 \pm 9.42$ \\
\hline MCP-1 & $25.33 \pm 1.13$ & $123.13 \pm 3.69$ & $517.74 \pm 20.61$ & $120.8 \pm 6.12$ & $250.4 \pm 6.07$ & $485.4 \pm 16.3$ \\
\hline $\mathrm{TNF} \alpha$ & $12.97 \pm 0.88$ & $55.97 \pm 3.47$ & $480.65 \pm 37.69$ & $124.7 \pm 7.8$ & $251.2 \pm 10.11$ & $511.2 \pm 27.81$ \\
\hline
\end{tabular}

Values are presented as the means \pm SD. IL, interleukin; VEGF, vascular endothelial growth factor; IFN, interferon; EGF, epidermal growth factor; MCP, monocyte chemotactic protein; TNF, tumor necrosis factor; $\mathrm{LH}$, lithium heparin.

and $\mathrm{TNF} \alpha$ levels were observed to be significantly increased from day 3 .

Within- and between-run precision. Results for within- and between-run precision revealed CV values $<10 \%$ for 3 control levels of the 12 cytokines tested (Tables II and III).

\section{Discussion}

In the present study, 12 cytokines/sample were measured simultaneously on a biochip platform. Results of various sample types obtained from 9 human volunteers demonstrated that concentrations of the 12 analyzed cytokines did not vary between serum in gel or glass tubes. However, levels were found to be significantly different between serum and plasma. IL-8, VEGF and EGF levels were lower in plasma compared with serum. VEGF in plasma was $>10$ times lower than in serum and EGF was $>60$ times lower. These observations may be associated with the blood agglutination process, since blood cells release a number of cytokines, including IL-8, VEGF and EGF, during the blood agglutination process. Therefore, the concentration of cytokines in plasma may reflect levels of various cytokines in the human body. By contrast, the standard deviation of the 12 cytokines was lower in plasma than in serum (Table I) and the levels of IL-8, VEGF and EGF were concentrated in a small area (Fig. 1). These results indicate that cytokine levels in plasma are more stable compared with serum. Therefore, plasma is a better matrix than serum for the evaluation of cytokines in clinical or research analyses.

Cytokines in serum and plasma were observed to be affected by multiple freeze/thaw cycles. In the present study 9 cytokines (IL-1 $\alpha,-2,-6$ and $-8, \mathrm{TNF} \alpha, \mathrm{EGF}, \mathrm{VEGF}, \mathrm{IFN} \gamma$ and MCP-1) of 3 sample types presented no significant changes in concentration following 10 freeze/thaw cycles, however, IL-1 $\beta$, -4 and -10 were found to increase significantly following
1 freeze/thaw cycle in serum and plasma and remained stable at increased levels for an additional 9 freeze/thaw cycles. These results indicate the importance of avoiding freeze/thaw cycles to minimize the risk of false values of cytokines. Where possible, determination of cytokine levels must be performed immediately following sample collection and if samples are stored frozen, levels must be determined at the same time to establish simultaneous comparison.

Following storage at $4^{\circ} \mathrm{C}$ for 6 days, levels of IL-1 $\alpha,-1 \beta$, $-2,-4,-6$ and -10, MCP-1 and IFN $\gamma$ in 6 sample types were unchanged. By contrast, IL-8, VEGF, TNF $\alpha$ and EGF concentrations were different. In separated serum samples in gel and glass tubes stored at $4^{\circ} \mathrm{C}$ for 6 days, no difference in levels of the cytokines was found. However, in unseparated serum in gel tubes, significant changes in the levels of 3 cytokines were observed. IL-8 increased following storage at $4^{\circ} \mathrm{C}$ for 3 days, EGF increased on day 4 and its concentration more than doubled from 18.98 to $38.30 \mathrm{ng} / \mathrm{l}$, increasing to $56.33 \mathrm{ng} / \mathrm{l}$ by day 6 , however TNF $\alpha$ decreased at day 6 . In separated plasma samples in LH tubes, EGF concentration increased on day 2. In unseparated plasma in LH tubes, 4 cytokines increased markedly. EGF levels increased extremely rapidly to $>6$ times that of baseline following storage at $4^{\circ} \mathrm{C}$ for $6 \mathrm{~h}$ and its concentration was $>500 \mathrm{ng} / \mathrm{l}$ at day 6 . VEGF increased on day 1 and by day 6 had increased by $>25$-fold. IL- 8 levels increased from day 2 and were 25 times higher than baseline at day 6 . TNF $\alpha$ increased from day 2 . These observations may be due to blood cells secreting these cytokines continuously, particularly EGF and VEGF. In unseparated serum samples in glass tubes, EGF concentration more than doubled following storage at $4^{\circ} \mathrm{C}$ for $6 \mathrm{~h}$ and at 6 days its concentration was $281.92 \mathrm{ng} / \mathrm{l}$. IL-8 and $\mathrm{TNF} \alpha$ increased from day 3 . These results demonstrate that plasma or serum must be separated immediately following centrifugation and cytokine concentrations in the sample must be measured as soon as possible. 
CV values $<10 \%$ were obtained for the within- and between-run precisions of the simultaneous immunoassays for the 12 cytokines assessed on EVIDENCE 180 for 3 concentrations. This result indicated that the cytokine biochip array had good stability and precision in measuring cytokines.

The use of a multi-analytical approach for the simultaneous measurement of 12 cytokines/sample using biochip array technology on the fully automated analyzer EVIDENCE 180 allows determination of cytokine levels in real time, which is advantageous for studies on the complex cytokine network and the role played by cytokines in normal and pathological processes. Assaying multiple cytokines in a single sample is likely to become an important technique in laboratory medicine. The knowledge gained from multiple cytokine analysis may enable improved diagnosis and disease management $(15,16)$.

In conclusion, the current study has identified improved methods for the detection of multiple cytokines in clinical and research analyses. Firstly, plasma cytokines accurately reflect levels of cytokines in the human body and a reduced number of factors compromise plasma levels compared with serum. Therefore, plasma is the most appropiate and stable sample type for the determination of multiple cytokine levels. Secondly, repeated freeze/thaw cycles of the samples must be avoided. Thirdly, storage at $4^{\circ} \mathrm{C}$ is likely to affect the concentration of a number of cytokines, therefore, plasma and serum must be separated immediately following centrifugation and the concentration of cytokines in the sample must be measured as soon as possible.

\section{Acknowledgements}

The current study was supported by grants from the Doctor Innovation Funding (11BCZ07) and the National Natural Science Funding (81071413), supported by the Chinese PLA General Hospital and Military Postgrad Medical College and the National Natural Science Foundation of China, respectively.

\section{References}

1. Berrahmoune H, Lamont JV, Herbeth B, FitzGerald PS and Visvikis-Siest S: Biological determinants of and reference values for plasma interleukin-8, monocyte chemoattractant protein-1, epidermal growth factor and vascular endothelial growth factor: Results from the STANISLAS cohort. Clin Chem 52: 504-510, 2006.
2. Beamer GL, Flaherty DK, Assogba BD, Stromberg P Gonzalez-Juarrero M, de Waal Malefyt R, Vesosky B and Turner J: Interleukin-10 promotes Mycobacterium tuberculosis disease progression in CBA/J mice. J Immunol 181: 5545-5550, 2008.

3. Londono D, Carvajal J, Arguelles-Grande C, Marques A and Cadavid D: Interleukin 10 protects the brain microcirculation from spirochetal injury. J Neuropathol Exp Neurol 67: 976-983, 2008.

4. Rautert R, Schinkothe T, Franklin J, Weihrauch M, Boll B, Pogge E, Bredenfeld H, Engert A, Diehl V and Re D: Elevated pretreatment interleukin-10 serum level is an International Prognostic Score (IPS)-independent risk factor for early treatment failure in advanced stage Hodgkin lymphoma. Leuk Lymphoma 49: 2091-2098, 2008.

5. Karadag F, Karul AB, Cildag O, Yilmaz M and Ozcan H: Biomarkers of systemic inflammation in stable and exacerbation phases of COPD. Lung 186: 403-409, 2008.

6. Kosmala W, Derzhko R, Przewlocka-Kosmala M, Orda A and Mazurek W: Plasma levels of TNF-alpha, IL-6 and IL-10 and their relationship with left ventricular diastolic function in patients with stable angina pectoris and preserved left ventricular systolic performance. Coron Artery Dis 19: 375-382, 2008.

7. Jha HC, Srivastava P, Sarkar R, Prasad J and Mittal A: Chlamydia pneumoniae IgA and elevated level of IL-6 may synergize to accelerate coronary artery disease. J Cardiol 52: 140-145, 2008.

8. Moreno I, Mir A, Vicente R, Pajares A, Ramos F, Vicente JL and Barbera M: Analysis of interleukin-6 and interleukin-8 in lung transplantation: correlation with nitric oxide administration. Transplant Proc 40: 3082-3084, 2008.

9. Nee L, O'Connell S, Nolan S, Ryan MP and McMorrow T: Nitric oxide involvement in TNF-alpha and IL-1 beta-mediated changes in human mesangial cell MMP-9 and TIMP-1. Nephron Exp Nephrol 110: e59-e66, 2008.

10. Cheung GT, Siow YL and O K: Homocysteine stimulates monocyte chemoattractant protein-1 expression in mesangial cells via NF-kappaB activation. Can J Physiol Pharmacol 86: 88-96, 2008.

11. Yasui T, Uemura H, Yamada M, Matsuzaki T, Tsuchiya N, Noguchi M, Yuzurihara M, Kase Y and Irahara M: Associations of interleukin-6 with interleukin-1beta, interleukin-8 and macrophage inflammatory protein-1beta in midlife women. Cytokine 41: 302-306, 2008.

12. Lee KY, Lee KS, Park SJ, Kim SR, Min KH, Choe YH and Lee YC: Clinical significance of plasma and serum vascular endothelial growth factor in asthma. J Asthma 45: 735-739, 2008.

13. Schoonenboom NS, Mulder C, Vanderstichele H, Van Elk EJ, Kok A, Van Kamp GJ, Scheltens P and Blankenstein MA: Effects of processing and storage conditions on amyloid beta (1-42) and tau concentrations in cerebrospinal fluid: implications for use in clinical practice. Clin Chem 51: 189-195, 2005.

14. Fitzgerald SP, Lamont JV, McConnell RI and Benchikh el O: Development of a high-throughput automated analyzer using biochip array technology. Clin Chem 51: 1165-1176, 2005

15. Matei I and Matei L: Cytokine patterns and pathogenicity in autoimmune diseases. Rom J Intern Med 40: 27-41, 2002.

16. Moser B and Willimann K: Chemokines: role in inflammation and immune surveillance. Ann Rheum Dis 63 (Suppl 2): ii84-ii89, 2004. 